\title{
Synthesis and characterization of Pd/ZSM-5/MCM-48 biporous catalysts with superior activity for benzene oxidation
}

\author{
Chi He ${ }^{\mathrm{a}}$, Peng $\mathrm{Li}^{\mathrm{a}}$, Jie Cheng ${ }^{\mathrm{a}}$, Hailin Wang ${ }^{\mathrm{a}}$, Jinjun $\mathrm{Li}^{\mathrm{a}}$, Qin $\mathrm{Li}^{\mathrm{b}, *}$, Zhengping Hao ${ }^{\mathrm{a}, * *}$ \\ a State Key Laboratory of Environmental Chemistry and Ecotoxicology, Research Center for Eco-Environmental Sciences, Chinese Academy of Sciences, Beijing 100085, China \\ ${ }^{\mathrm{b}}$ Department of Chemical Engineering, Curtin University of Technology, Perth, Western Australia 6845, Australia
}

\section{A R T I C L E I N F O}

\section{Article history:}

Received 2 November 2009

Received in revised form 1 April 2010

Accepted 17 April 2010

Available online 5 May 2010

\section{Keywords:}

In situ overgrowth

ZSM-5/MCM-48

Acidity

Superior activity

VOCs

\begin{abstract}
A B S T R A C T
ZSM-5/MCM-48 composite materials with different acidities and enhanced thermal stability have been synthesized via a simple and reliable in situ overgrowth method. The as-prepared biporous materials and the Pd-impregnated catalysts were systematically investigated by various techniques, including XRD, ICP-OES, $\mathrm{N}_{2}$ adsorption/desorption, $\mathrm{H}_{2}$ chemisorption, SEM, TEM/HRTEM, FT-IR, ${ }^{27} \mathrm{Al}$ MAS NMR, $\mathrm{NH}_{3}-$ TPD, $\mathrm{H}_{2}$-TPR and XPS. The characterization results reveal that all composite catalysts exhibit high surface area, large pore volume and long pore diameter. The quantity of acid sites increases as the ZSM-5 additive amount increases, and $\mathrm{Al}$ atoms are in the tetrahedral coordination positions in composite materials. The activity tests demonstrate that all the Pd-loaded catalysts are active in the total elimination of benzene, while the catalytic activity values of Pd-loaded ZSM-5/MCM-48 composite catalysts are much higher than those of $\mathrm{Pd} / \mathrm{ZSM}-5$ or $\mathrm{Pd} / \mathrm{MCM}-48$ alone. Both $\mathrm{Pd}^{0}$ and $\mathrm{Pd}^{2+}$ are responsible for the oxidation reaction, and the catalytic activities are primarily related to the support acidity and the Pd dispersion. In addition, the stability of the composite catalysts also improves with an appropriate amount of ZSM-5 additives in MCM-48. This research shows that the novel Pd-loaded composite catalysts are promising materials in the elimination of VOCs.
\end{abstract}

(c) 2010 Elsevier B.V. All rights reserved.

\section{Introduction}

The increasing environmental awareness has prompted the emergence of stricter regulations upon automobile utility and chemical and petrochemical processes [1]. Among these, the reduction of volatile organic compounds (VOCs) is particularly important [2]. Particularly, benzene is a notorious hazardous VOC present in various industries, such as chemical, petrochemical, paint and coating, and steel manufacturers [1]. VOCs catalytic oxidation technology has been identified as one of the most efficient ways due to its clear advantages, such as high destructive efficiency, low operation and energy cost, and a relatively high flexibility [3]. The proper selection and development of the catalyst is essential for achieving an efficient VOC removal [4]. Currently, different types of catalysts such as supported noble metals, metal oxides, and their mixtures are widely investigated in VOCs catalytic oxidation studies [4-7]. Among them, noble-metal-based (e.g. Pd and Pt) catalysts show the highest activity [5,8]. Particularly, Pd-based catalysts were extensively investigated as Pd was promising for practical applications in hydrocarbon deep oxidation due to its high activity at relatively low

\footnotetext{
* Corresponding author. Tel.: +61 89266 7704; fax: +61 892667704.

** Corresponding author. Tel.: +86 10 62923564; fax: +86 1062923564 .

E-mail addresses: Q.Li@curtin.edu.au (Q. Li), zpinghao@rcees.ac.cn (Z. Hao).
}

temperature and its high tolerance to the moisture $[9,10]$. On the other hand, researchers have found that the catalyst support plays an important role in the generation of active species and in the catalytic performance for the Pd-loaded catalysts [11,12]. For instance, Niwa and co-workers [13] proposed that the activity of Pd-based catalysts was very much dependent on the acid-base character of the supports. They further demonstrated that the Brønsted acid sites were responsible for the generation of dispersed Pd species, and that the acid-base property of the support can significantly influence the dispersion and oxidation state of Pd [11,14,15].

Zeolite and zeolite-like materials have been widely used as adsorbents and catalysts due to their uniform pore sizes, large internal surfaces, strong intrinsic acidities and high hydrothermal stabilities [16,17]. Especially, ZSM-5 zeolite possesses high resistance to deactivation, i.e., coke deposition, owing to its unique properties such as uniform pore channels and suitable acidity [18]. Unfortunately, these materials possess a limited application towards bulky molecules due to their small pore sizes $(<1.5 \mathrm{~nm})$ [19]. Over the last decade, the discovery of mesoporous materials, such as M41S (pore sizes $=2-30 \mathrm{~nm}$ ), has overcome the diffusion limitations of microporous zeolites and these materials have wide potential application [20]. However, M41S materials generally exhibit weak acidity and low hydrothermal stability due to their amorphous frameworks. As a consequence, new synthesis strategies have been developed to obtain materials which com- 
bine the advantages of mesoporous materials and those of zeolites [21-36]. For example, Corma et al. [21] reported a post-synthesis dealumination process via steaming or acid leaching on full-grown zeolites. However, these structures create only a minor improvement in mass transfer as either the mesoporous network is not connected or the mesopores are not linked to the outer surface. Recently, a procedure for controlled desilication of zeolites was obtained and the mesopores became interconnected [24]. Unfortunately, this method relies on destruction of part of the zeolite to form the mesopores, which could be problematic in terms of reproducibility. Carbon nanofibers or carbon black aggregates have also been used as templates in zeolite synthesis, and the mesopores can be produced in zeolite structure via a post-synthesis procedure [25-27]. Moreover, the same procedure can be used with carbon replicas or inverse replicas as a template [28-30].

Over the last couple of years, several simple and reliable approaches have been developed to form micro/mesoporous combined materials using zeolite nanoparticles or zeolite seeds as the silica source [31-36]. However, most of the published reports on composite catalysts have focused on one-dimensional materials (such as MCM-41 or SBA-15) as the mesostructured component, although three-dimensional materials, such as cubic MCM-48, are more interesting from the viewpoint of catalysis due to the interwoven pore system, which allows the sufficient diffusion of reactants within the pores, subsequently leading to a better catalytic performance [37]. Prokešová et al. [38] synthesized Beta/MCM-48 composite materials via simultaneous hydrothermal treatment. However, the simultaneous hydrothermal process is complicated and often demands a long synthesis period. Mokaya and co-worker [37] reported an interesting recrystallization approach to obtain ZSM-5/MCM-48 composite materials. More recently, Liu et al. [39] reported a very simple approach for the synthesis of Y/MCM-48 biporous material using an overgrowth method, and the synthesized composite material possesses stronger acidity and higher hydrothermal stability than MCM-48.

In this paper, we report the synthesis of ZSM-5/MCM-48 biporous materials with different acidities by a simple and reproducible in situ overgrowth procedure. We also demonstrate that such a micro/mesoporous composite material can be effectively applied in VOCs catalytic oxidation. The objectives of this work are: (1) to investigate the in situ overgrowth method for the preparation of a new type of Pd-supported biporous materials and its application in benzene catalytic oxidation; (2) to explore whether and how the support acidity affects the dispersion and state of Pd; and (3) to correlate the textural properties (surface area, pore volume and pore diameter), the Pd state and dispersion with the catalytic activity of the Pd-supported catalysts for benzene oxidation.

\section{Experimental}

\subsection{Catalyst synthesis}

The ZSM-5/MCM-48 composite materials were synthesized by adding different amounts of ZSM-5 zeolite ( $\mathrm{Si} / \mathrm{Al}=25$, Tianjin Chemical Plant) to a preformed MCM-48 colloidal precursor. Typically, $11.34 \mathrm{~g}$ of cetyltrimethylammonium bromide (CTAB) was dissolved in $74.25 \mathrm{ml}$ of $\mathrm{H}_{2} \mathrm{O}$, followed by adding $1.44 \mathrm{~g}$ of $\mathrm{NaOH}$ and $15.6 \mathrm{~g}$ of tetraethyl orthosilicate (TEOS) under stirring. After that, the required amounts of ZSM- 5 were added and the mixture was stirred for $2 \mathrm{~h}$ at room temperature; the result material was then transferred into an autoclave and aged at $110^{\circ} \mathrm{C}$ for $5 \mathrm{~h}$. The resulting solid material was obtained by filtration, dried at $100^{\circ} \mathrm{C}$ and calcined at $550^{\circ} \mathrm{C}$ for $6 \mathrm{~h}$. In this work, four samples with different ZSM-5 additive amounts, denoted as ZM- $x(x=5,10,20$ and $30)$, were prepared.
For comparison, pure MCM-48 was synthesized following the procedure established for the preparation of the composite materials (no ZSM-5 zeolite was added). Moreover, a mechanical mixture of ZSM-5 zeolite (10 wt.\%) and MCM-48, denoted as ZM-mixed, was also prepared.

The Pd catalysts with a nominal Pd loading of $1.0 \mathrm{wt}$ \% were prepared by impregnating the porous support with a $\mathrm{PdCl}_{2}$ aqueous solution and drying at $100^{\circ} \mathrm{C}$ overnight, followed by calcination at $500^{\circ} \mathrm{C}$ for $4 \mathrm{~h}$ and reduction in a pure $\mathrm{H}_{2}$ stream $(30 \mathrm{ml} / \mathrm{min})$ at $480^{\circ} \mathrm{C}$ for $2 \mathrm{~h}$.

\subsection{Catalyst characterization}

X-ray diffraction (XRD) patterns were recorded on a Rigaku TTR2 powder diffraction system using $\mathrm{Cu} \mathrm{K} \alpha$ radiation $(\lambda=0.15418 \mathrm{~nm})$ in the $2 \theta$ range of $0.7-4^{\circ}$ (scanning rate of $0.5^{\circ} / \mathrm{min}$ ) and $5-50^{\circ}$ (scanning rate of $4 \% \mathrm{~min}$ ), respectively. The exact Pd wt.\% in all calcined samples was determined by inductively coupled plasma optical emission spectroscopy (ICP-OES) on an OPTIMA 2000. The palladium dispersion was assessed by $\mathrm{H}_{2}$ chemisorption at $25^{\circ} \mathrm{C}$, i.e., the molar ratio of $\mathrm{H} / \mathrm{Pd}$ [40]. The mean Pd crystallite size was further estimated from the equation: $d(n m)=112 /$ (percentage of Pd exposed) [41], assuming that the Pd crystallites were spherical with a surface atom density of $1.27 \times 10^{9}$ atoms $/ \mathrm{m}^{2} . \mathrm{N}_{2}$ adsorption/desorption isotherms of catalysts at $77 \mathrm{~K}$ were collected on a gas sorption analyzer NOVA1200. All the samples were degassed under vacuum at $300^{\circ} \mathrm{C}$ for $3 \mathrm{~h}$ before the measurement. The total pore volume was estimated from the amount of nitrogen adsorbed at a relative pressure $\left(P / P_{0}\right)$ of $c a$. 0.99 . The specific surface area $\left(S_{\mathrm{BET}}\right)$ was calculated with the Brunauer-Emmett-Teller (BET) method (the micropore surface area and micropore volume were estimated by the $t$-plot method) and the pore size distribution(PSD) was derived from the desorption branch of the $\mathrm{N}_{2}$ isotherm using the Barrett-Joyner-Halenda (BJH) method. Infrared spectra were recorded using a Nicolet Nexus670 IR spectrometer by measuring the absorbance of the $\mathrm{KBr}$ pellet (2\% sample, $98 \% \mathrm{KBr}$ ). Scanning electron microscopy (SEM) images were recorded on a Hitachi S-3000N microscope equipped with an EDAX detector for composition analysis of the as-synthesized catalysts. Transmission electron microscopy (TEM) images were collected on a Hitachi H-7500 microscope operating at an accelerating voltage of $80 \mathrm{kV}$. All samples were ground, dispersed in ethanol and deposited on the copper grids prior to observation. High resolution transmission electron microscope (HRTEM) images were collected on a FEI Tecnai G2 F20 U-TWIN microscope operating at an accelerating voltage of $200 \mathrm{kV}$. All samples were ground, dispersed in ethanol and deposited on the micro-grids prior to observation. Solid-state ${ }^{27}$ Al MAS NMR spectra was performed on a Bruker AC-80MHZ spectrometer equipped with a $5 \mathrm{~mm}$ BBI detector, the spinning frequency was $8 \mathrm{kHz}$, and the chemical shifts were referred to $\mathrm{Al}\left(\mathrm{H}_{2} \mathrm{O}\right)_{6}{ }^{3+}$. Temperature programmed desorption of $\mathrm{NH}_{3}\left(\mathrm{NH}_{3}\right.$-TPD) were preformed on a Micromeritics chemisorb 2720 . Typically, $0.05 \mathrm{~g}$ of the catalyst was pre-treated in a helium flow $(50 \mathrm{ml} / \mathrm{min})$ at $300^{\circ} \mathrm{C}$ for $1 \mathrm{~h}$ and then cooled to room temperature prior to adsorption of $\mathrm{NH}_{3} / \mathrm{He}\left(2 \% / 98 \%\right.$, v/v). After being saturated with $\mathrm{NH}_{3}$, the catalyst was flushed with $\mathrm{He}(50 \mathrm{ml} / \mathrm{min})$ for $1 \mathrm{~h}$ at room temperature to remove the physisorbed $\mathrm{NH}_{3}$. Then the desorption profile of $\mathrm{NH}_{3}$ TPD was recorded from 25 to $600^{\circ} \mathrm{C}$ at a heating rate of $10^{\circ} \mathrm{C} / \mathrm{min}$. Temperature programmed reduction (TPR) experiments were performed on a Micromeritics chemisorb 2720. Prior to reduction, $0.1 \mathrm{~g}$ of the catalyst was dried in a helium flow $(50 \mathrm{ml} / \mathrm{min})$ at $300^{\circ} \mathrm{C}$ for $1 \mathrm{~h}$. Then the sample was reduced under a $\mathrm{H}_{2} / \mathrm{He}(2 \% / 98 \%$, $\mathrm{v} / \mathrm{v}$ ) mixture from 25 to $500^{\circ} \mathrm{C}$ with a heating rate of $10^{\circ} \mathrm{C} / \mathrm{min}$. $\mathrm{X}$-ray photoelectron spectroscopy (XPS) experiments were carried out on a Thermo Electron Escalab250 instrument using $\mathrm{Al}$ $\mathrm{K} \alpha$ as the exciting radiation at a constant pass energy of $50 \mathrm{eV}$. 


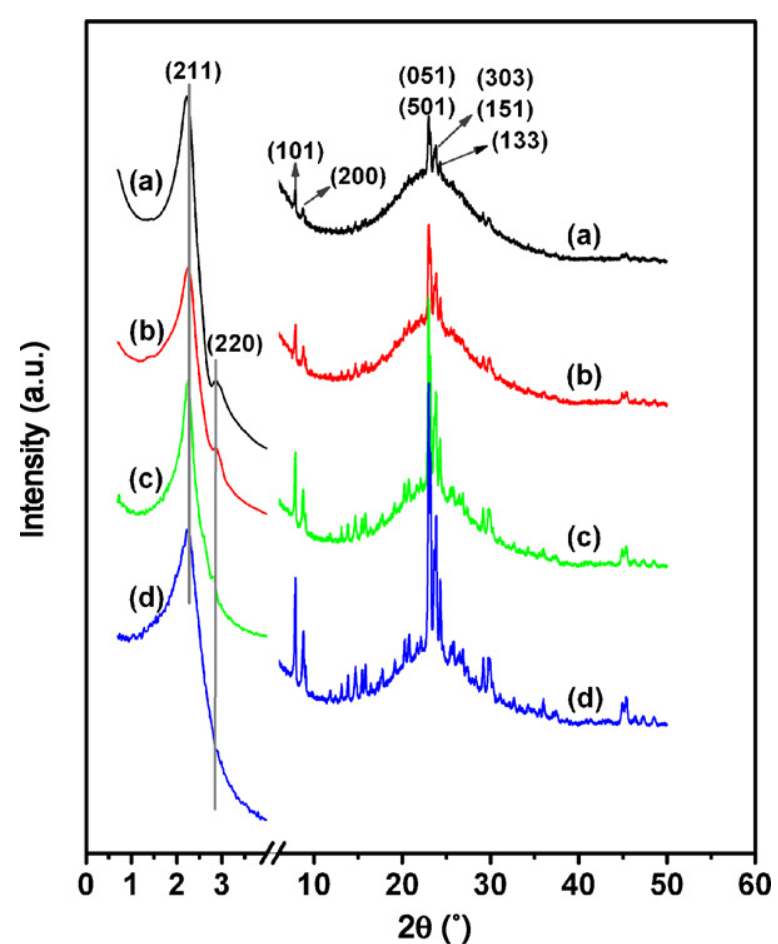

Fig. 1. X-ray diffraction patterns of synthesized catalysts: (a) Pd/ZM-5\%, (b) Pd/ZM$10 \%$, (c) Pd/ZM-20\% and (d) Pd/ZM-30\%.

The $C 1 \mathrm{~s}$ peak $(285.0 \mathrm{eV})$ was used to calibrate the binding energy (BE).

\subsection{Catalytic oxidation of benzene}

All evaluation experiments were performed in a continuousflow fixed-bed reactor under atmospheric pressure; the instrument consisted of a stainless steel tube $(6 \mathrm{~mm}$ i.d.) that was filled with the required amount of the catalyst. The VOC-containing gas was generated by bubbling air through the VOC saturator, and then further diluted with another air stream before reaching the reaction bed. The temperatures of the catalyst bed and at the tubular electric furnace were monitored automatically by E-type thermocouples. In each test, $300 \mathrm{mg}$ of catalyst (40-60 mesh) was placed at the middle of a tube reactor and the total flow rate was kept at $350 \mathrm{ml} / \mathrm{min}$, i.e., a gas hourly space velocity (GHSV) of $32,000 \mathrm{~h}^{-1}$, and the $\mathrm{O}_{2}$ feed concentration was kept at about $21 \mathrm{v} / \mathrm{v} \%$. Before each test, the catalytic bed temperature was raised to $130^{\circ} \mathrm{C}$ with the feed stream passing (no oxidation was detected) and stabilized for $30 \mathrm{~min}$. Then the catalyst bed was heated at a heating rate of $5^{\circ} \mathrm{C} / \mathrm{min}$ to the next temperature and stabilized for $20 \mathrm{~min}$ prior to online analysis of the effluent gas composition in an Agilent 6820 gas chromatograph equipped with an FID and a TCD. VOC concentrations in the feed and effluent streams were determined with the FID after being separated in an AB-GASPRO capillary column, and $\mathrm{CO} / \mathrm{CO}_{2}$ in the effluent stream were separated in a TDX-01 column and their concentrations were determined with the TCD.

\section{Results}

\subsection{Structural features of the composite materials}

XRD patterns in the $2 \theta$ range of $0.7-4^{\circ}$ and $5-50^{\circ}$ for the $\mathrm{Pd}-$ supported composite catalysts are shown in Fig. 1. The XRD patterns of Pd/ZM-5\%, Pd/ZM-10\% and Pd/ZM-20\% are typical of the MCM48 mesophase, belonging to the Ia3d space group [16,38,42], with

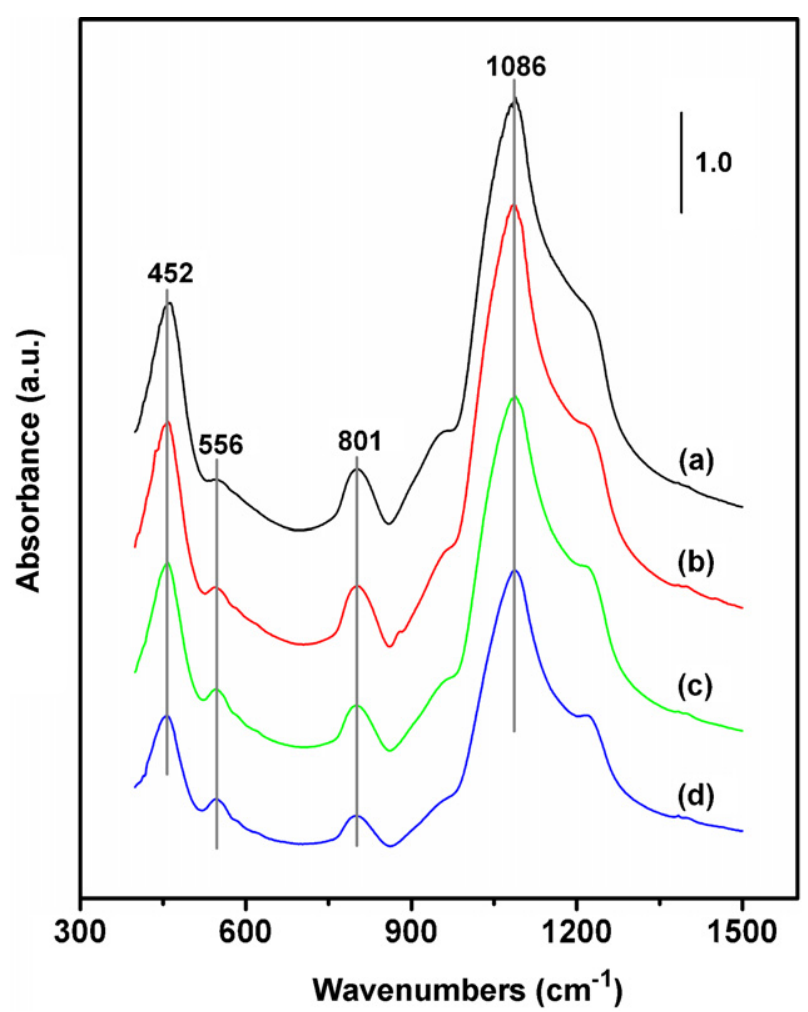

Fig. 2. FT-IR spectra of composite catalysts: (a) Pd/ZM-5\%, (b) Pd/ZM-10\%,(c) Pd/ZM$20 \%$ and (d) Pd/ZM-30\%.

the (211) and (220) diffraction peaks appearing at $2 \theta$ values of $2.3^{\circ}$ and $2.9^{\circ}$, respectively. Simultaneously, the zeolite phase is featured with many sharp peaks in the range of $10-40^{\circ}$. It is further noted that the structure order of MCM-48 decreases with the increase of the ZSM-5 additive amount. Overall, the $2 \theta$ values of all composite samples are a little lower than that of MCM-48, and this probably be ascribed to the interfacial effect between ZSM-5 zeolite and mesoporous MCM-48 phase ( $\mathrm{Si}-\mathrm{O}-\mathrm{Al}$ structure) [39]. These results suggest that a structurally ordered cubic MCM- 48 was successfully grown onto ZSM-5 zeolite, to form biporous (micro- and mesoporous) materials hybridized with a ZSM-5 zeolite phase and a cubic MCM-48 phase.

Fig. 2 shows the FT-IR spectra of synthesized composite catalysts. The bands at $c a .452,801$ and $1086 \mathrm{~cm}^{-1}$ are due to the symmetric/asymmetric bending and stretching vibrations of Si-O-Si bonds [39]. Particularly, the bands at $\mathrm{ca} .560 \mathrm{~cm}^{-1}$ are attributed to the five- and six-membered rings of $\mathrm{T}-\mathrm{O}-\mathrm{T}(\mathrm{T}=\mathrm{Si}$ or $\mathrm{Al}$ ) in zeolite $[23,31,43,44]$, thus further evidencing the presence of zeolite subunits in composite samples.

The particle morphology of the composite catalysts shows that there are two types of particles (supplementary materials, Fig. S1): hexagonal/cubic (ZSM-5 zeolite) and spherical particles (MCM-48) [45]. It is worth noting that the zeolite particles are interconnected with the spherical particles in some cases. With respect to the elemental composition, the $\mathrm{Si} / \mathrm{Al}$ ratio is lower than the expected value in all cases (Fig. S1 and Table 1), suggesting that Al was incorporated into the solid products. The structure pore ordering and morphology of Pd/ZM-5\% were further probed with transmission electron microscopy (TEM, Fig. 3A) and high resolution transmission electron microscopy (HRTEM, Fig. 3B-D). It can be seen that the ZSM-5 zeolite surface is covered with the MCM-48 layers, and the MCM48 phase possesses well-ordered pore structure with uniform pore size of $c a .3 .47 \mathrm{~nm}$ (Fig. 3A). The constitution of the mesoporous MCM-48 phase growing around ZSM-5 zeolite is also observed in 
Table 1

Characteristic data and catalytic activity of catalysts.

\begin{tabular}{|c|c|c|c|c|c|c|c|}
\hline Sample & $\mathrm{Pd}^{\mathrm{a}}(\%)$ & Si/Al ratio ${ }^{b}$ & $\mathrm{H} / \mathrm{Pd}^{\mathrm{c}}$ & $D_{\mathrm{c}}{ }^{\mathrm{d}}(\mathrm{nm})$ & $T_{10}{ }^{\mathrm{e}}\left({ }^{\circ} \mathrm{C}\right)$ & $T_{50}{ }^{\mathrm{e}}\left({ }^{\circ} \mathrm{C}\right)$ & $T_{90}{ }^{\mathrm{e}}\left({ }^{\circ} \mathrm{C}\right)$ \\
\hline Pd/ZM-5\% & 0.97 & 221.7 & 0.59 & 1.89 & 183 & 200 & 209 \\
\hline Pd/ZM-10\% & 0.96 & 128.3 & 0.57 & 1.96 & 188 & 207 & 214 \\
\hline Pd/ZM-20\% & 0.98 & 74.7 & 0.51 & 2.19 & 192 & 215 & 229 \\
\hline Pd/ZM-30\% & 0.97 & 63.2 & 0.49 & 2.28 & 195 & 219 & 237 \\
\hline Pd/MCM-48 & 0.97 & - & 0.48 & 2.33 & 204 & 245 & 292 \\
\hline Pd/ZSM-5 & 0.96 & 25 & 0.39 & 2.87 & 186 & 224 & 244 \\
\hline
\end{tabular}

a Actual Pd contents obtained by the ICP-OES analysis.

b Actual Si/Al ratio estimated by the EDS analysis.

c Molar ratio of adsorbed hydrogen atoms to the total palladium atoms.

d Calculated diameters of the palladium crystallites based on the dispersion of Pd.

e Temperatures at which $10 \%, 50 \%$ and $90 \%$ conversion of benzene occur.

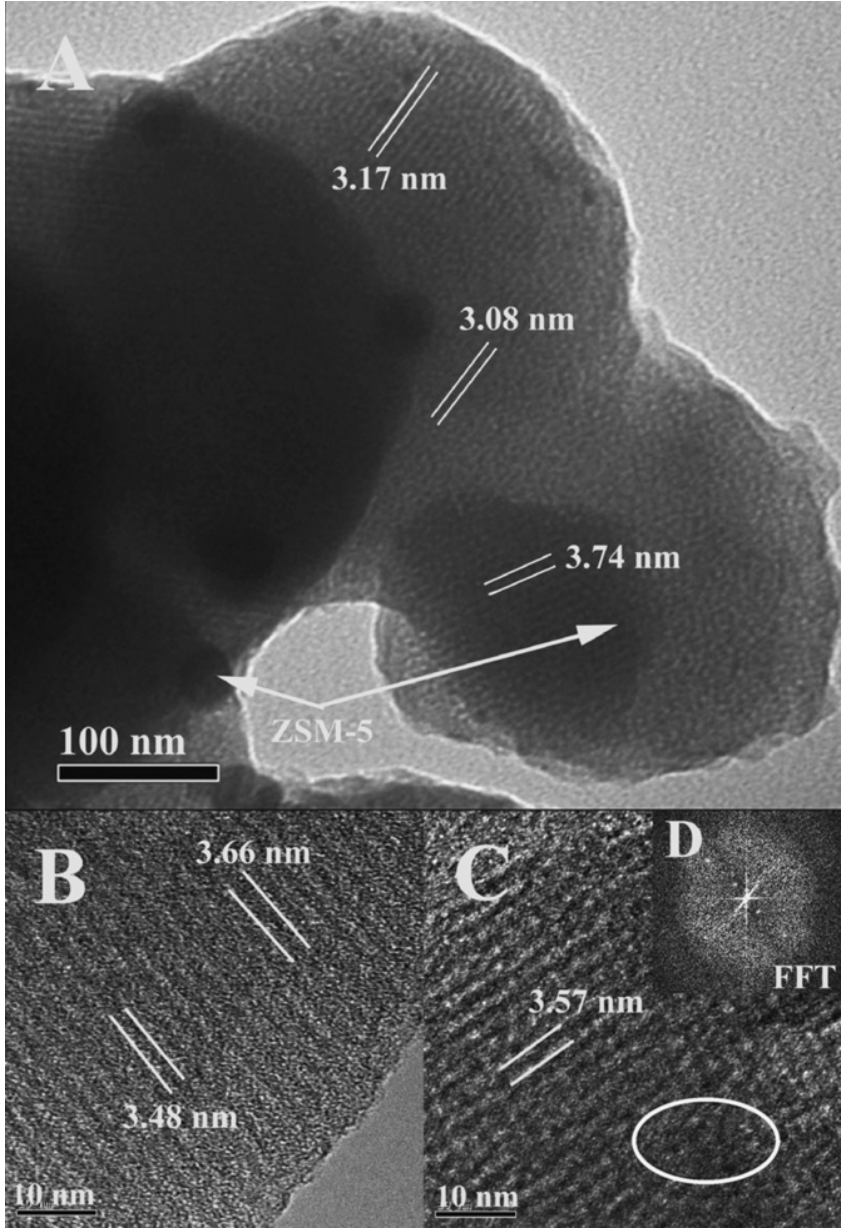

Fig. 3. TEM (A) and HRTEM (B and C) images of Pd/ZM-5\%. Insert (D) is the selectedarea FFT patterns.

HRTEM images, which further confirms our assumption about the formation process of ZSM-5/MCM-48 composite in our experiment.

Fig. 4 shows the ${ }^{27}$ Al MAS NMR spectra of Pd/ZM-5\% and Pd/ZM$10 \%$. Both spectra only exhibit a resonance at $54.9 \mathrm{ppm}$ assigned to the tetrahedral coordinated $\mathrm{Al}$ [46], suggesting that the $\mathrm{Al}$ atoms are tetrahedrally coordinated and incorporated into the framework of the composite catalysts.

\subsection{Textural properties of the composite catalysts}

The $\mathrm{N}_{2}$ adsorption/desorption isotherms and the $\mathrm{BJH}$ pore size distribution calculated from the desorption branch of the isotherms for Pd/ZM- $x$ and Pd/MCM-48 (Fig. 5) show that all composite samples exhibit a typical type IV adsorption/desorption isotherms

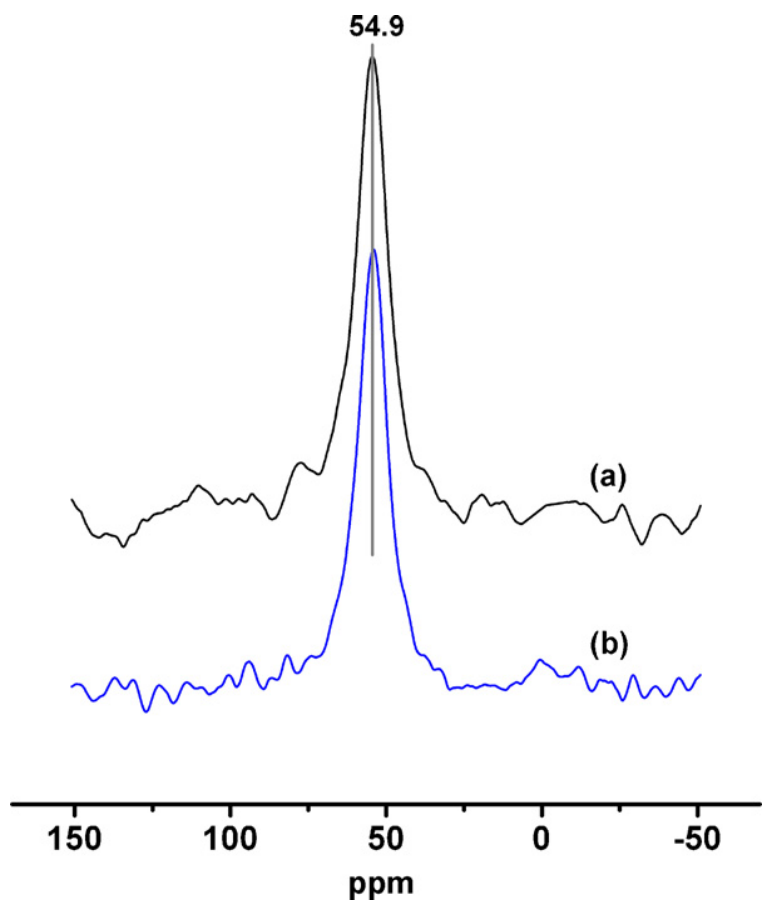

Fig. 4. ${ }^{27} \mathrm{Al}$ MAS NMR spectra of (a) Pd/ZM-5\% and (b) Pd/ZM-10\%.

with well expressed $\mathrm{H} 1$-type hysteresis loops at relative pressures $P / P_{0}=0.2-0.45$ [47], indicating that the presence of the frameworkconfined mesopores [42]. On the other hand, the isotherms suggest that all the composite catalysts possess broader pore size distribution than MCM-48, as the steep rise of MCM-48 at $P / P_{0}=0.2-0.45$ shows (Fig. 5B). Table 2 lists the specific surface area $\left(S_{\mathrm{BET}}\right)$, mean pore diameter $\left(D_{\mathrm{p}}\right)$, total pore volume $\left(D_{\mathrm{v}}\right)$, micropore surface area $\left(S_{\mathrm{Mi}-\mathrm{BET}}\right)$ and micropore volume $\left(D_{\mathrm{Mi}-\mathrm{V}}\right)$ of fresh and used catalysts. In particular, Pd/ZM-5\% possesses the largest $S_{\mathrm{BET}}\left(1040 \mathrm{~m}^{2} / \mathrm{g}\right), D_{\mathrm{V}}$ $\left(1.074 \mathrm{~cm}^{3} / \mathrm{g}\right)$ and $D_{\mathrm{p}}(4.1 \mathrm{~nm})$ values. Similarly, the other three composite catalysts also possess high $S_{\text {BET }}\left(915.9-1014 \mathrm{~m}^{2} / \mathrm{g}\right)$, which is slightly smaller than that of Pd/MCM-48 $\left(1029 \mathrm{~m}^{2} / \mathrm{g}\right)$ but much larger than Pd/ZSM-5 $\left(326.4 \mathrm{~m}^{2} / \mathrm{g}\right)$. In contrast, both $D_{\mathrm{V}}$ $\left(0.821-1.074 \mathrm{~cm}^{3} / \mathrm{g}\right)$ and $D_{\mathrm{p}}(3.4-4.1 \mathrm{~nm})$ of the composite catalysts are much larger than the mesoporous $\mathrm{Pd} / \mathrm{MCM}-48\left(0.810 \mathrm{~cm}^{3} / \mathrm{g}\right.$ and $2.4 \mathrm{~nm}$ ). Moreover, the $S_{\mathrm{BET}}$ and $D_{\mathrm{v}}$ contributed by micropores (i.e., $S_{\mathrm{Mi}-\mathrm{BET}}$ and $\left.D_{\mathrm{Mi}-\mathrm{V}}\right)$ increase with the increase of the ZSM-5 zeolite additive amount according to the $t$-plot method (Fig. 1 and Table 2). For comparison, textural properties of the composite materials and the mechanical mixture are also presented in Table 2 . All the $S_{\mathrm{BET}}, D_{\mathrm{v}}$ and $D_{\mathrm{p}}$ of $\mathrm{Pd} / \mathrm{ZM}-10 \%$ are higher than the values of the mechanical mixture $\left(810.2 \mathrm{~m}^{2} / \mathrm{g}, 0.741 \mathrm{~cm}^{3} / \mathrm{g}\right.$ and $\left.2.5 \mathrm{~nm}\right)$.

The $\mathrm{NH}_{3}$-TPD was performed to evaluate the acid strength and acid site quantity of the synthesized catalysts, as displayed 
Table 2

Textural properties of fresh and used catalysts.

\begin{tabular}{|c|c|c|c|c|c|}
\hline Sample & $S_{\text {BET }}{ }^{\text {a }}\left(\mathrm{m}^{2} / \mathrm{g}\right)$ & $D_{\mathrm{v}}^{\mathrm{b}}\left(\mathrm{cm}^{3} / \mathrm{g}\right)$ & $S_{\text {Mi-BET }}^{c}\left(\mathrm{~m}^{2} / \mathrm{g}\right)$ & $D_{\mathrm{Mi}-\mathrm{V}}^{\mathrm{d}}\left(\mathrm{cm}^{3} / \mathrm{g}\right)$ & $D_{\mathrm{p}}{ }^{\mathrm{e}}(\mathrm{nm})$ \\
\hline Pd/ZM-5\% & 1040 & 1.074 & 27.9 & 0.023 & 4.1 \\
\hline $\mathrm{Pd} / \mathrm{ZM}-10 \%$ & 1014 & 0.995 & 58.3 & 0.048 & 3.8 \\
\hline $\mathrm{Pd} / \mathrm{ZM}-20 \%$ & 946.8 & 0.884 & 117.5 & 0.127 & 3.7 \\
\hline $\mathrm{Pd} / \mathrm{ZM}-30 \%$ & 915.9 & 0.821 & 214.3 & 0.188 & 3.4 \\
\hline Pd/ZM-mixed & 810.2 & 0.741 & - & - & 2.5 \\
\hline Pd/MCM-48 & 1029 & 0.810 & - & - & 2.4 \\
\hline Pd/ZSM-5 & 326.4 & 0.208 & 297.9 & 0.150 & - \\
\hline Pd/ZM-5\%-used & 952.4 & 0.937 & 49.9 & 0.092 & 3.9 \\
\hline Pd/ZM-10\%-used & 886.8 & 0.891 & 87.2 & 0.101 & 3.5 \\
\hline Pd/ZM-20\%-used & 702.3 & 0.664 & 171.1 & 0.160 & 3.1 \\
\hline Pd/ZM-30\%-used & 592.1 & 0.596 & 353.4 & 0.263 & 2.3 \\
\hline Pd/MCM-48-used & 747.9 & 0.543 & - & - & 2.1 \\
\hline Pd/ZSM-5-used & 298.1 & 0.152 & 252.3 & 0.114 & - \\
\hline
\end{tabular}

a BET specific surface area.

b Total pore volume estimated at $P / P_{0}=0.99$.

c Micropore surface area estimated from the $t$-plot method.

d Micropore volume estimated from the $t$-plot method.

e $\mathrm{BJH}$ pore diameter calculated from the desorption branch.

in Fig. 6. The desorption temperature and quantitative mole number of acid sites are listed in Table 3. In general, all the composite catalysts exhibit two desorption peaks in the range of $70-390^{\circ} \mathrm{C}$, which means that there are two types of acid sites. Particularly, Pd/ZM-30\% has the largest quantities of acid sites (desorption peaks at 81 and $368{ }^{\circ} \mathrm{C}$ ) (Table 3). The amount of strong acid sites (desorption peak $>360^{\circ} \mathrm{C}$ in this work) in the composite catalysts increases with the increase of the ZSM-5 additive amount (from 0.02 to $0.21 \mathrm{mmol} \mathrm{NH}_{3} /$ g-cat.), while there is no certain trend for the number of weak acid sites (desorption peak $<110^{\circ} \mathrm{C}$ ). Overall, the total acid site quantity of the composite catalysts increases with the increase of the ZSM-5 additive amount (Table 3).

TPR profiles of the Pd-supported composite catalysts are shown in Fig. 7. Only a negative peak $\left(60-80^{\circ} \mathrm{C}\right)$ can be observed for all samples due to the desorption of weakly adsorbed hydrogen and the decomposition of $\mathrm{PdH}_{x}[48,49]$, indicating that $\mathrm{PdCl}_{2}$ or $\mathrm{PdO}$ gets reduced easily to metal $\mathrm{Pd}$ in $\mathrm{H}_{2}$ atmosphere at ambient temperature [50], which is also expected to occur in the hydrocarbon atmosphere. On the other hand, many researchers have proposed that the decomposition temperature and inten- sity of the desorption peak increases with the decrease of Pd dispersion [50,51]. In this research, the temperature (from 62 to $78^{\circ} \mathrm{C}$ ) and intensity of the desorption peaks increase when raising the ZSM-5 additive amount (Fig. 7), indicating the reduction of the Pd dispersion, i.e., the increase of the Pd particle size. Table 1 lists the H/Pd molar ratio and the calculated average palladium particle size of the prepared catalysts. In general, the $\mathrm{H} / \mathrm{Pd}$ ratio of $\mathrm{ZM}-x$ supported catalysts (0.49-0.59) appear to be higher than the ratios of materials supported on ZSM-5 zeolite (0.39) and MCM-48 (0.48), and the H/Pd ratio increases with the decrease of the ZSM-5 additive amount (Table 1). Moreover, the calculated Pd crystallite size on ZM-5\% (ca. $2.03 \mathrm{~nm}$ ) is smaller than that from the TEM images ( $c a .2 .5 \mathrm{~nm}$ ), probably because many Pd particles are too small to be observed, so that only larger visible Pd particles can be counted in TEM images (Fig. 3A).

\subsection{Catalytic activity}

The light-off curves were used to compare the activity of the synthesized catalysts for benzene catalytic oxidation, as shown

Table 3

Acidities of as-synthesized composite catalysts.

\begin{tabular}{|c|c|c|c|c|c|}
\hline \multirow[t]{2}{*}{ Sample } & \multicolumn{2}{|c|}{ Desorption peak temperature $\left({ }^{\circ} \mathrm{C}\right)$} & \multicolumn{3}{|c|}{ Acidity $^{\mathrm{a}}$ (mmol NH$/$ /g-cat.) } \\
\hline & I & II & I & II & $\mathrm{I}+\mathrm{II}$ \\
\hline $\mathrm{Pd} / \mathrm{ZM}-5 \%$ & 79 & 361 & 0.15 & 0.02 & 0.17 \\
\hline Pd/ZM-10\% & 102 & 386 & 0.07 & 0.13 & 0.20 \\
\hline Pd/ZM-20\% & 109 & 362 & 0.10 & 0.14 & 0.24 \\
\hline Pd/ZM-30\% & 81 & 368 & 0.16 & 0.21 & 0.37 \\
\hline Pd/MCM-48 & 229 & - & 0.02 & - & 0.02 \\
\hline $\mathrm{Pd} / \mathrm{ZSM}-5$ & 245 & 408 & 0.15 & 0.26 & 0.41 \\
\hline
\end{tabular}

a Amounts of $\mathrm{NH}_{3}$ desorbed at different temperatures.

Table 4

Summary of the better known catalysts for benzene oxidation.

\begin{tabular}{|c|c|c|c|c|}
\hline \multirow[t]{2}{*}{ Sample } & \multicolumn{2}{|l|}{ Conditions } & \multirow[t]{2}{*}{$T_{90}\left({ }^{\circ} \mathrm{C}\right)$} & \multirow[t]{2}{*}{ Reference } \\
\hline & $C_{\mathrm{Bz}}{ }^{\mathrm{a}}(\mathrm{ppm})$ & $\operatorname{GHSV}\left(\mathrm{h}^{-1}\right)$ & & \\
\hline $\mathrm{Pd} / \mathrm{V}_{2} \mathrm{O}_{5} / \mathrm{Al}_{2} \mathrm{O}_{3}$ & 482 & 30,000 & 270 & [1] \\
\hline $\mathrm{Pt}-\mathrm{Pd} / \gamma-\mathrm{Al}_{2} \mathrm{O}_{3}$ & 1000 & 15,000 & 225 & [52] \\
\hline Pd/Ce/Al-PILC ${ }^{b}$ & $130-160$ & 20,000 & 250 & [53] \\
\hline $\mathrm{Cu} / \mathrm{MnO}_{x}-\mathrm{CeO}_{2}$ & 200 & 30,000 & 235 & [54] \\
\hline Pd/Nd-SBA-15 & 1000 & 100,000 & 219 & {$[55]$} \\
\hline Pd/ZM-5\% & 1500 & 32,000 & 209 & This work \\
\hline
\end{tabular}

\footnotetext{
a Benzene inlet concentration.
}

b Alumina pillared clays. 

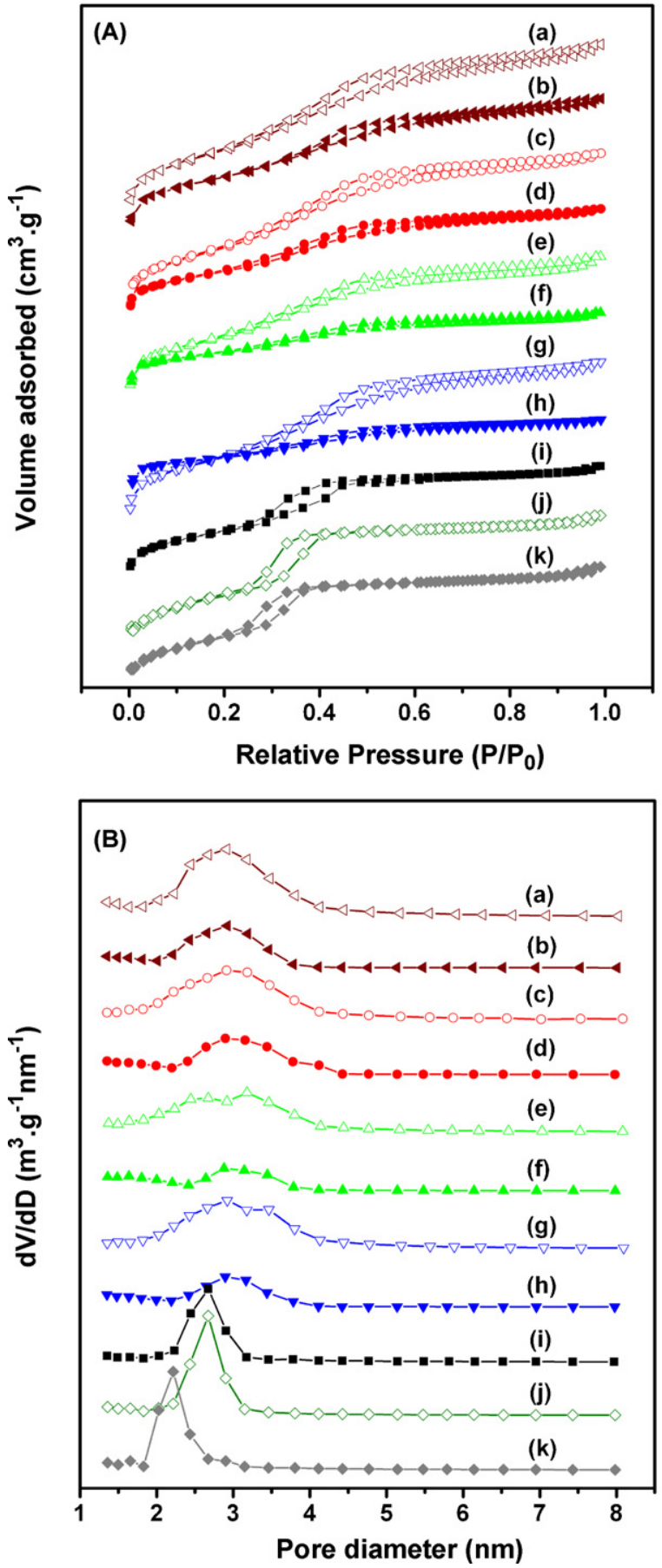

Fig. 5. $\mathrm{N}_{2}$ adsorption/desorption isotherms (A) and pore size distribution (B) of various catalysts: (a) Pd/ZM-5\%, (b) Pd/ZM-5\%-used, (c) Pd/ZM-10\%, (d) Pd/ZM-10\%used, (e) Pd/ZM-20\%, (f) Pd/ZM-20\%-used, (g) Pd/ZM-30\%, (h) Pd/ZM-30\%-used, (i) Pd/ZM-mixed, (j) Pd/MCM-48 and (k) Pd/MCM-48-used.

in Fig. 8. The products detected in the effluent are only $\mathrm{CO}_{2}$ and $\mathrm{H}_{2} \mathrm{O}$. Generally, the composite catalysts (complete oxidation occurs in the vicinity of $235^{\circ} \mathrm{C}$ ) are more active than the Pd/ZSM-5 (complete oxidation occurs at $270^{\circ} \mathrm{C}$ ) and Pd/MCM-48 (complete oxidation occurs at $315^{\circ} \mathrm{C}$ ). Table 1 presents the reaction temperatures of $T_{10}, T_{50}$ and $T_{90}$ for benzene conversion over these catalysts. Pd/ZM-5\% possesses the highest activity with $90 \%$ of benzene conversion at $209^{\circ} \mathrm{C}$. The temperature reduction is more than $80^{\circ} \mathrm{C}$ compared with $\mathrm{Pd} / \mathrm{MCM}-48$ that causes $90 \%$ of benzene conversion at $292^{\circ} \mathrm{C}$. In comparison with other active catalysts

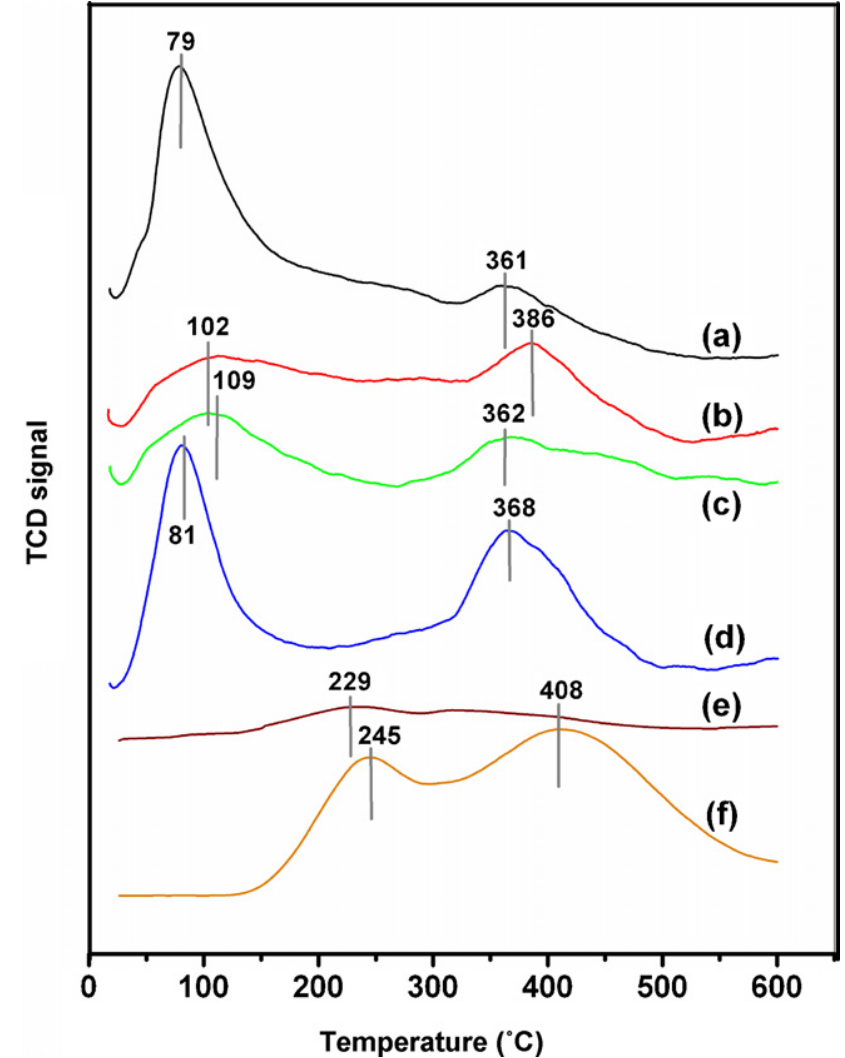

Fig. 6. $\mathrm{NH}_{3}-\mathrm{TPD}$ curves of composite catalysts: (a) $\mathrm{Pd} / \mathrm{ZM}-5 \%$, (b) $\mathrm{Pd} / \mathrm{ZM}-10 \%$, (c) Pd/ZM-20\%, (d) Pd/ZM-30\%, (e) Pd/MCM-48 and (f) Pd/ZSM-5.

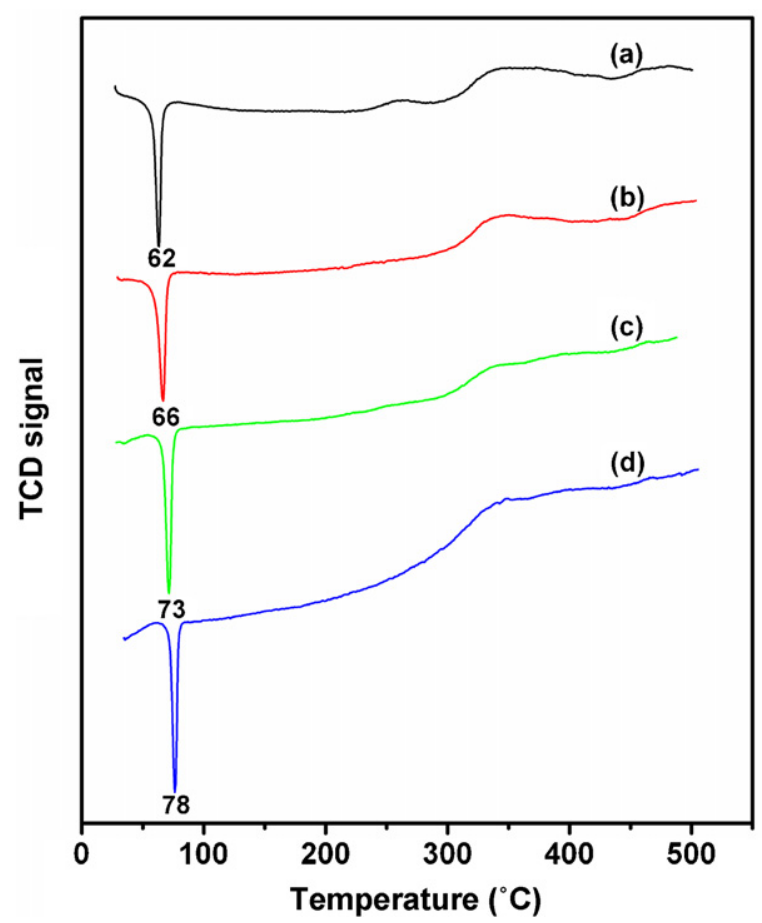

Fig. 7. $\mathrm{H}_{2}$-TPR profiles of (a) Pd/ZM-5\%, (b) Pd/ZM-10\%, (c) Pd/ZM-20\% and (d) $\mathrm{Pd} / \mathrm{ZM}-30 \%$. 


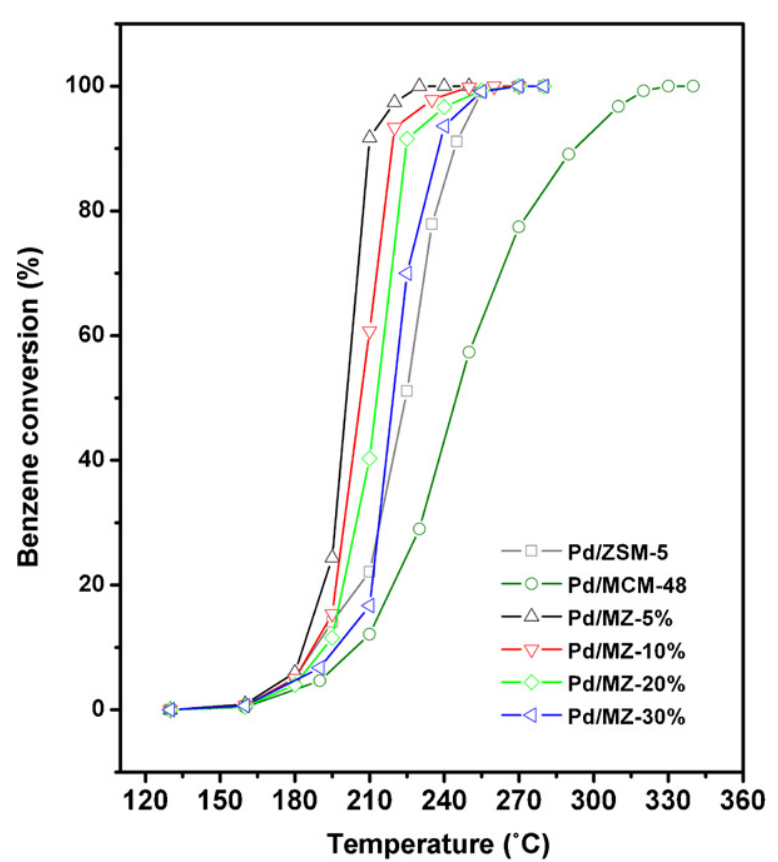

Fig. 8. Conversion profiles of benzene oxidation over various Pd-loaded catalysts.

reported elsewhere [52-55], our catalysts perform better in deep catalytic oxidation of benzene, as shown in Table 4. According to $T_{50}$ (Table 1 ), the activity order of synthesized catalysts is as follows: Pd/ZM-5\% $\left(200^{\circ} \mathrm{C}\right)>\mathrm{Pd} / \mathrm{ZM}-10 \%\left(207^{\circ} \mathrm{C}\right)>\mathrm{Pd} / \mathrm{ZM}-20 \%$ $\left(215^{\circ} \mathrm{C}\right)>\mathrm{Pd} / \mathrm{ZM}-30 \% \quad\left(219^{\circ} \mathrm{C}\right)>\mathrm{Pd} / \mathrm{ZSM}-5 \quad\left(224^{\circ} \mathrm{C}\right)>\mathrm{Pd} / \mathrm{MCM}-48$ $\left(245^{\circ} \mathrm{C}\right)$.

XPS spectra of fresh and used Pd/ZM-5\% catalysts are shown in Fig. 9. The binding energies of $\mathrm{Pd} 3 \mathrm{~d}_{5 / 2}$ and $\mathrm{Pd} 3 \mathrm{~d}_{3 / 2}$ are found at around 335.1 and $341.4 \mathrm{eV}$ for the fresh catalyst, indicating the presence of $\mathrm{Pd}^{0}[50,56]$. As for the used $\mathrm{Pd} / \mathrm{ZM}-5 \%$ catalyst, the Pd $3 d$ binding energies centered at $335.1 \mathrm{eV}\left(\mathrm{Pd} \mathrm{3d_{5/2 }}\right), 337.2 \mathrm{eV}$

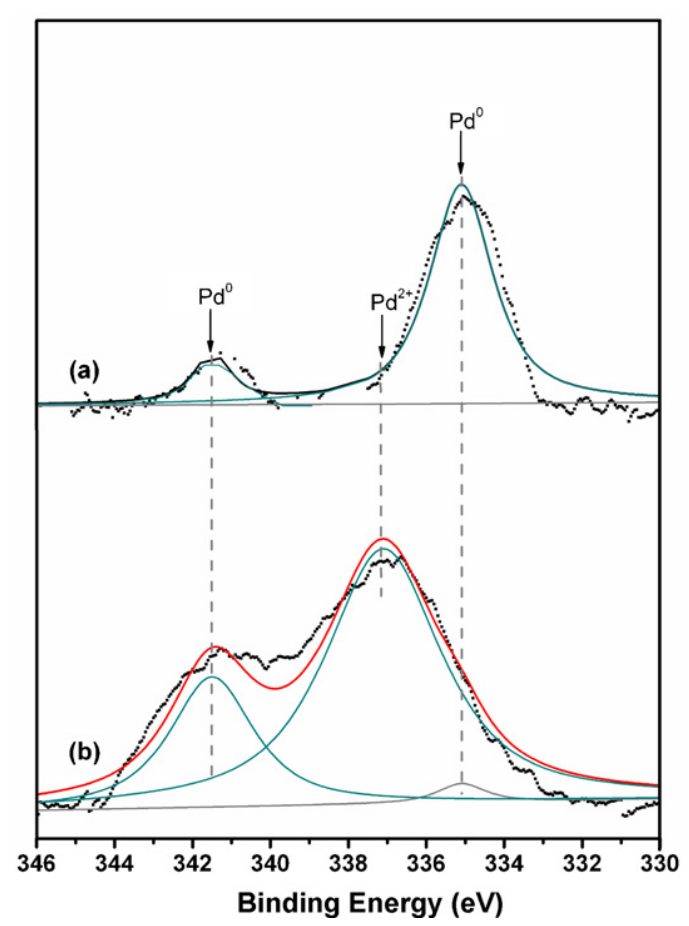

Fig. 9. XPS spectra of (a) Pd/ZM-5\% and (b) Pd/ZM-5\%-used.
$\left(\mathrm{Pd} 3 \mathrm{~d}_{5 / 2}\right)$ and $341.5 \mathrm{eV}\left(\mathrm{Pd} 3 \mathrm{~d}_{3 / 2}\right)$, which can be attributed to $\mathrm{Pd}^{0}$ (335.1 and $341.5 \mathrm{eV}$ ) and $\mathrm{Pd}^{2+}(337.2 \mathrm{eV}$ ) [57], respectively. It is also noted that fresh $\mathrm{Pd} / \mathrm{ZM}-5 \%$ only contains $\mathrm{Pd}^{0}$ while the used one predominantly contains the $\mathrm{Pd}^{2+}$ species.

\section{Discussion}

The ZSM-5/MCM-48 composite materials with various acidities have been successfully prepared by a simple in situ overgrowth approach and all Pd impregnated materials are powerful catalysts for benzene total oxidation.

\subsection{Pd dispersion on the prepared catalysts}

In most cases, a larger surface area of the support is beneficial to the active phase dispersion. However, the Pd dispersion in this work is not only determined by the specific surface area. For instance, $\mathrm{Pd} / \mathrm{MCM}-48$ possesses a relatively low Pd dispersion $\left(D_{\mathrm{c}}=2.33 \mathrm{~nm}\right)$ although it possesses a large specific surface area (Tables 1 and 2). Muto et al. and Okumura et al. [11,13,15] reported that the support acid property plays an important role in VOCs catalytic activity, because the acid sites can determine the Pd dispersion on the support. Similarly, in our previous work, we also found that Pd atoms are inclined to disperse on the support with a larger surface area and more acid sites (especially the strong acid sites) [58]. Considering the catalyst acidity, we anticipate that both the specific surface area and the acidity could promote the Pd dispersion (Table 1).

\subsection{Benzene oxidation activity and the textural properties of the catalysts}

It is widely accepted that the support nature (acidity and textural properties) $[11,15,50]$ and the active phase state (valence state and dispersion) [59-61], can affect the catalyst activity. There are different reports in the literature regarding the effect of the Pd state on hydrocarbons catalytic oxidation [57]. With regard to the active phase in VOCs oxidation over Pd-supported catalyst, i.e., $\mathrm{Pd}^{0}, \mathrm{Pd}^{2+}$ or their mixture phase, most researchers proposed that $\mathrm{Pd}^{2+}$ is active in hydrocarbon oxidation, and the presence of $\mathrm{Pd}^{0}$ can promote the catalytic activity by providing more active sites for VOCs dissociation and allowing the overall reaction to proceed more rapidly [2,51,59,62]. The Mars-van Krevelen model is usually applied to hydrocarbons oxidation over Pd-loaded catalysts [63], which assumes that the reaction occurs when a reactant molecule interacts with an oxygen-rich portion of the catalyst, and a portion of the catalyst surface is alternately reduced $\left(\mathrm{Pd}^{0}\right)$ and oxidized $\left(\mathrm{PdO}_{x}\right) . \mathrm{H}_{2}$-TPR result shows that $\mathrm{Pd}^{2+}$ gets reduced easily to metal $\mathrm{Pd}$ in $\mathrm{H}_{2}$ atmosphere at ambient temperature (Fig. 7). This result is in good agreement with the XPS measurement (Fig. 9). When $\mathrm{O}_{2}$ is present in the reactant feed mixture, a portion of $\mathrm{Pd}^{0}$ become oxidized to active $\left[\mathrm{Pd}^{2+} \mathrm{O}^{2-}\right.$ ] species [64], suggesting that both the $\mathrm{Pd}^{0}$ and $\mathrm{Pd}^{2+}$ are responsible for the oxidation reaction. Firstly, the oxidized catalyst $\left(\left[\mathrm{Pd}^{2+} \mathrm{O}^{2-}\right]\right)$ is reduced by benzene and at the same time the benzene is oxidized to $\mathrm{CO}_{2}$ and $\mathrm{H}_{2} \mathrm{O}$. And then the catalyst redox center $\left(\mathrm{Pd}^{0}\right)$ is oxidized by the $\mathrm{O}_{2}$ stream to recover the active oxidized centers through adsorption and dissociation of $\mathrm{O}_{2}$. In this work, it is worth noting that the activity order is not fully consistent with the Pd dispersion as the activity of Pd/ZSM-5 $\left(T_{50}=224^{\circ} \mathrm{C}\right)$ is superior to that of Pd/MCM-48 $\left(T_{50}=245^{\circ} \mathrm{C}\right)$ although Pd/ZSM5 possesses a lower Pd dispersion (Pd particles diameter: $2.87 \mathrm{~nm}$ ) (Fig. 8 and Table 1). In addition, the specific surface area of Pd/ZSM$5\left(326.4 \mathrm{~m}^{2} / \mathrm{g}\right)$ is also smaller than that of Pd/MCM-48 $\left(1029 \mathrm{~m}^{2} / \mathrm{g}\right)$ (Table 2). Many researchers reported that Pd particles loaded on acidic supports were more easily oxidized than those supported on the neutral or basic support as the acidic supports with elec- 


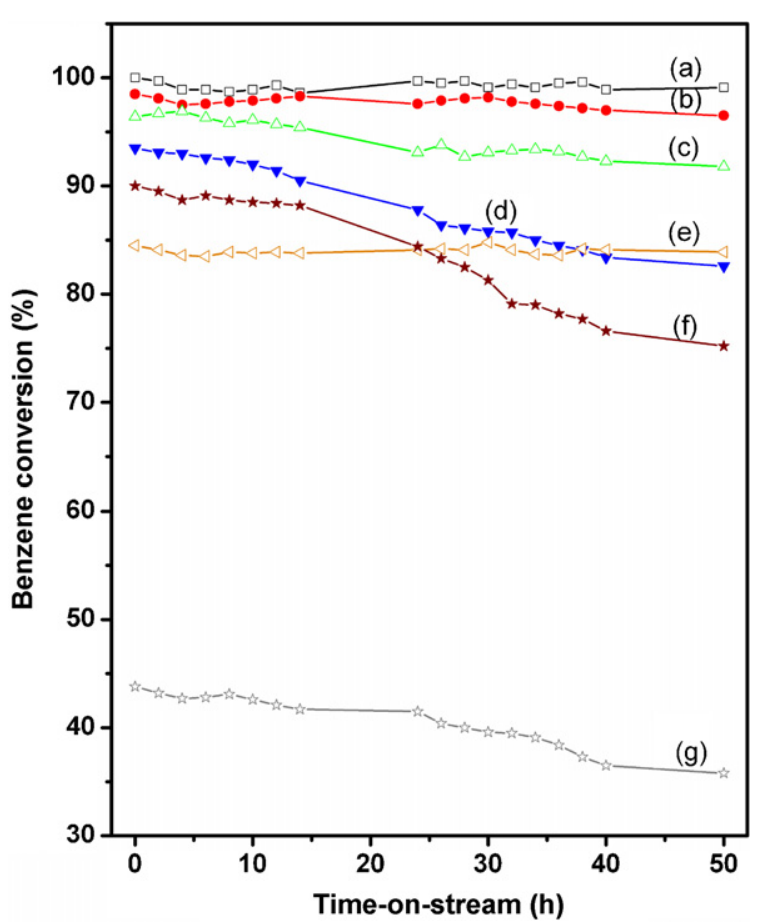

Fig. 10. Stability tests for benzene oxidation with time-on-stream over synthesized catalysts at $240^{\circ} \mathrm{C}$, benzene $=1500 \mathrm{ppm}, \mathrm{GHSV}=32,000 \mathrm{~h}^{-1}:$ (a) Pd/ZM-5\%, (b) Pd/ZM-10\%, (c) Pd/ZM-20\%, (d) Pd/ZM-30\%, (e) Pd/ZSM-5 and (f and g) Pd/MCM-48. (For $(\mathrm{f})$, the reaction temperature $=290^{\circ} \mathrm{C}$.)

trophilic character resulted in the electron deficiency on Pd atoms $[11,13,15]$, and the acceleration of $\mathrm{Pd}^{0} \rightarrow \mathrm{Pd}^{2+}$ can also promote the catalytic reaction according to the Mars-van Krevelen model (the second step). As a consequence, we expect that the acidity and Pd dispersion may have a synergetic effect on benzene catalytic oxidation, as the acidity of Pd/ZSM-5 (0.41 $\mathrm{mmol} \mathrm{NH}_{3} /$ g-cat.) is much higher than that of Pd/MCM-48 (0.02 $\mathrm{mmol} \mathrm{NH}_{3} /$ g-cat.) (Table 3$)$.

\subsection{Stability of the prepared catalysts}

To evaluate the thermal stability of the prepared catalysts, we characterized the used samples by $\mathrm{N}_{2}$ adsorption/desorption, XRD and TGA, as shown in Table 1, Figs. S2 and S3. Pd/ZM-5\% and Pd/ZM$10 \%$ possess good thermal stability (Table 2 ), and the XRD result reveals that the structures of the used Pd/ZM-5\% and Pd/ZM-10\% are well preserved (Fig. S2). The stability of the composite catalysts decreases on further increases of the ZSM- 5 content. According to the surface area changes before and after the catalytic reaction, the thermal stability order decreases as follows: $\mathrm{Pd} / \mathrm{ZM}-5 \% \approx \mathrm{Pd} / \mathrm{ZSM}-$ $5>\mathrm{Pd} / \mathrm{ZM}-10 \%>\mathrm{Pd} / \mathrm{ZM}-20 \%>\mathrm{Pd} / \mathrm{MCM}-48>\mathrm{Pd} / \mathrm{ZM}-30 \%$ (Table 2 ). On the other hand, the catalytic test conditions, such as the formation of $\mathrm{H}_{2} \mathrm{O}$ during the reaction, may lead to a partial breakdown of the materials or a formation of coke on the supports. It is generally accepted that coke is able to deactivate the catalyst and thus reduce the catalytic activity. Therefore, it is significant to understand the coke during the oxidation reaction. Fig. S3 shows that only an endothermic peak centered at about $80^{\circ} \mathrm{C}$ can be observed for all used samples due to the desorption of adsorbed and molecular water [19]. It is noteworthy that no mass loss can be found when the temperature is higher than $200^{\circ} \mathrm{C}$, indicating that no coke was formed on these composite catalysts. Moreover, the benzene conversion with time-on-stream over the synthesized catalysts was evaluated, as shown in Fig. 10. During the $50 \mathrm{~h}$ test, the activities of Pd/MCM-48 and Pd/ZM-30\% are gradually reduced. However, it is important to note that the benzene conversions over Pd/ZM-5\%,
Pd/ZM-10\% are well sustained, indicating a better stability than the pure mesoporous catalyst.

\section{Conclusions}

In this work, the ZSM-5/MCM-48 composite materials with different acid strength values and enhanced thermal stability have been successfully synthesized via a simple and reproducible in situ overgrowth approach. The synthesized composite catalysts were extensively characterized and their catalytic activities for benzene oxidation were also tested. The prepared materials are integrated composites of ZSM-5 zeolite and MCM-48 and show significant differences from their mechanically mixed counterpart. All composite catalysts exhibit high surface area and possess large pore volume and diameter. Moreover, the Al atoms are tetrahedrally coordinated and incorporated into the composite materials, and the acidity of the composite materials is much stronger than that of the pure MCM-48. Interestingly, the thermal stability of the composite catalysts is dependent on the ZSM-5 additive amount. All Pd-loaded composite materials act as active catalysts for benzene oxidation, where both the $\mathrm{Pd}^{0}$ and $\mathrm{Pd}^{2+}$ are responsible for the oxidation reactions. They all demonstrate improved catalytic activity compared to Pd/MCM-48, in particular, Pd/ZM-5\% shows the most superior catalytic activity, reducing the $90 \%$ benzene conversion temperature from $292^{\circ} \mathrm{C}(\mathrm{Pd} / \mathrm{MCM}-48)$ to $209^{\circ} \mathrm{C}$. Their superior catalytic activity can be explained in terms of the support acidity and the improved Pd dispersion. These novel Pd-loaded composite catalysts are promising materials for eliminating VOCs in air, and probably have other potential applications in adsorption and separation.

\section{Acknowledgements}

The National Basic Research Program of China (No. 2010CB732300), the National High Technology Research and Development Program of China (No. 2006AA06A310), and National Science Fund for Distinguished Young Scholars (No. 20725723) are gratefully acknowledged.

\section{Appendix A. Supplementary data}

Supplementary data associated with this article can be found, in the online version, at doi:10.1016/j.apcata.2010.04.033.

\section{References}

[1] R.S.G. Ferreira, P.G.P. de Oliveira, F.B. Noronha, Appl. Catal. B: Environ. 50 (2004) 243-249.

[2] H.L. Tidahy, S. Siffert, J.-F. Lamonier, R. Cousin, E.A. Zhilinskaya, A. Aboukaïs, B.L. Su, X. Canet, G. De Weireld, M. Frère, J.-M. Giaudon, G. Leclercq, Appl. Catal. B: Environ. 70 (2007) 377-383.

[3] J.J. Li, X.Y. Xu, Z. Jiang, Z.P. Hao, C. Hu, Environ. Sci. Technol. 39 (2005) $1319-1323$.

[4] M. Ferrandon, E. Björnbom, J. Catal. 200 (2001) 148-159.

[5] J. Carpentier, J.-F. Lamonier, S. Siffert, E.A. Zhilinskaya, A. Aboukaïs, Appl. Catal. A: Gen. 234 (2002) 91-101.

[6] Y. Liu, M. Luo, Z. Wei, Q. Xin, P. Ying, C. Li, Appl. Catal. B: Environ. 29 (2001) 61-67.

[7] M. Labaki, S. Siffert, J.-F. Lamonier, E.A. Zhilinskaya, A. Aboukaïs, Appl. Catal. B: Environ. 43 (2003) 261-271.

[8] T. Maillet, C. Solleau, J. Barbier, D. Duprez, Appl. Catal. B: Environ. 14 (1997) 85-95.

[9] T. Garcia, B. Solsona, D.M. Murphy, K.L. Antcliff, S.H. Taylor, J. Catal. 229 (2005) 1-11.

[10] T. Garcia, B. Solsona, D. Cazorla-Amoros, A. Linares-Solano, S.H. Tayor, Appl. Catal. B: Environ. 62 (2006) 66-76.

[11] K. Okumura, T. Kobayashi, H. Tanaka, M. Niwa, Appl. Catal. B: Environ. 44 (2003) 325-331.

[12] W. Lin, L. Lin, Y.X. Zhou, Y.C. Xie, K. Scheurell, E. Kemnitz, J. Mol. Catal. A: Chem 226 (2005) 263-268.

[13] K. Muto, N. Katada, M. Niwa, Appl. Catal. A: Gen. 134 (1996) 203-215.

[14] K. Okumura, J. Amano, N. Yasunobu, M. Niwa, J. Phys. Chem. B 104 (2000) 1050-1057. 
[15] K. Okumura, S. Matsumoto, N. Nishiaki, M. Niwa, Appl. Catal. B: Environ. 40 (2003) 151-159.

[16] A. Corma, Chem. Rev. 97 (1997) 2373-2420.

[17] M.E. Davis, Nature 417 (2002) 813-821.

[18] Y.Q. Song, X.X. Zhu, Y. Song, Q.X. Wang, L.Y. Xu, Appl. Catal. A: Gen. 302 (2006) 69-77.

[19] C.J. Van Oers, W.J.J. Stevens, E. Bruijn, M. Mertens, O.I. Lebedev, G. Van Tendeloo, V. Meynen, P. Cool, Micropor. Mesopor. Mater. 120 (2009) 29-34.

[20] C.T. Kresge, M.E. Leonowicz, W.J. Roth, J.C. Vartuli, J.S. Beck, Nature 359 (1992) 710-712.

[21] A. Corma, V. Fornes, S.B. Pergher, T.L. Maessen, J.G. Buglass, Nature 396 (1998) 353-356.

[22] P. Kortunov, S. Vasenkov, J. Kärger, R. Valiullin, P. Gottschalk, M. Fé Elià, M. Perez, M. Stöcker, B. Drescher, G. McElhiney, C. Berger, R. Gläser, J. Weitkamp, J. Am. Chem. Soc. 127 (2005) 13055-13059.

[23] D.T. On, S. Kaliaguine, Angew. Chem. Int. Ed. 40 (2001) 3248-3251.

[24] J.C. Groen, W. Zhu, S. Brouwer, S.J. Huynink, F. Kapteijn, J.A. Moulijn, J. PérezRamirez, J. Am. Chem. Soc. 129 (2007) 355-360.

[25] C.J.H. Jacobsen, C. Madsen, J. Houzvicka, I. Schmidt, A. Carlsson, J. Am. Chem. Soc. 122 (2000) 7116-7117.

[26] I. Schmidt, A. Boisen, E. Gustavsson, K. Stahl, S. Pehrson, S. Dahl, A. Carlsson, C.J.H. Jacobsen, Chem. Mater. 13 (2001) 4416-4418.

[27] K. Egeblad, C.H. Christensen, M. Kustova, C.H. Christensen, Chem. Mater. 20 (2008) 946-960.

[28] S. Jun, S. Hoon Joo, R. Ryoo, M. Kruk, M. Jaroniec, Z. Liu, T. Ohsuna, O. Terasaki, J. Am. Chem. Soc. 122 (2000) 10712-10713.

[29] A. Sakthivel, S.J. Huang, W.H. Chen, Z.H. Lan, K.H. Chen, T.W. Kim, R. Ryoo, A.S.T. Chiang, S.B. Liu, Chem. Mater. 16 (2004) 3168-3175.

[30] M. Tiemann, Chem. Mater. 20 (2008) 961-971.

[31] Y. Liu, W. Zhang, T.J. Pinnavaia, Angew. Chem. Int. Ed. 40 (2001) 1255-1258.

[32] J. Liu, X. Zhang, Y. Han, F.-S. Xiao, Chem. Mater. 14 (2002) 2536-2540.

[33] F.S. Xiao, Y. Han, Y. Yu, X. Meng, M. Yang, S. Wu, J. Am. Chem. Soc. 124 (2002) 888-889.

[34] S.P.B. Kremer, C.E.A. Kirschhock, M. Tielen, F. Collignon, P.J. Grobet, P.A. Jacobs, J.A. Martens, Adv. Funct. Mater. 12 (2002) 286-292.

[35] S.P.B. Kremer, C.E.A. Kirschhock, A. Aerts, K. Villani, J.A. Martens, O.I. Lebedev, G. Van Tendeloo, Adv. Mater. 15 (2003) 1705-1707.

[36] Y. Liu, T.J. Pinnavaia, J. Mater. Chem. 14 (2004) 1099-1103.

[37] Y.D. Xia, R. Mokaya, J. Mater. Chem. 14 (2004) 3427-3435.

[38] P. Prokešová, S. Mintova, J. Čejka, T. Bein, Micropor. Mesopor. Mater. 64 (2003) 165-174.
[39] Y.H. Zhang, Y.C. Liu, Y.X. Li, Appl. Catal. A: Gen 345 (2008) 73-79.

[40] N. Krishnankutty, J. Li, M.A. Vannice, Appl. Catal. A: Gen. 173 (1998) 137-144.

[41] J.J. Li, Z. Jiang, Z.P. Hao, X.Y. Xu, Y.H. Zhuang, J. Mol. Catal. A: Chem. 225 (2005) $173-179$.

[42] J.S. Beck, J.C. Vartuli, W.J. Roth, M.E. Leonowicz, C.T. Kresge, K.D. Schmitt, C.T.W. Chu, D.H. Olson, E.W. Sheppard, S.B. McCullen, J.B. Higgins, J.L. Schlenkert, J. Am. Chem. Soc. 114 (1992) 10834-10843.

[43] J.Y. Ying, C.P. Mehnert, M.S. Wong, Angew. Chem. Int. Ed. 38 (1999) 56-77.

[44] Y. Liu, W. Zhang, T.J. Pinnavaia, J. Am. Chem. Soc. 122 (2000) 8791-8792.

[45] Y.D. Xia, R. Mokaya, J. Mater. Chem. 14 (2004) 863-870.

[46] V.N. Shetti, J. Kim, R. Srivastava, M. Choi, R. Ryoo, J. Catal. 254 (2008) 296-303.

[47] P.T. Tanev, T.J. Pinnavaia, Science 267 (1995) 865-867.

[48] M. Bonarowska, J. Pielaszek, V.A. Semikolenov, Z. Karpinski, J. Catal. 209 (2002) 528-538.

[49] L.M. Gomez-Sainero, X.L. Seoane, J.L.G. Fierro, A. Arcoya, J. Catal. 209 (2002) 279-288.

[50] P. Sangeetha, K. Shanthi, K.S. Rama Rao, B. Viswanathan, P. Selvam, Appl. Catal. A: Gen. 353 (2009) 160-165.

[51] N.K. Nag, J. Phys. Chem. B 105 (2001) 5945-5949.

[52] H.S. Kim, T.W. Kim, H.L. Koh, S.H. Lee, B.R. Min, Appl. Catal. A: Gen. 280 (2005) $125-131$.

[53] S.F. Zuo, R.X. Zhou, Micropor. Mesopor. Mater. 113 (2008) 472-480.

[54] X.F. Tang, Y.D. Xu, W.J. Shen, Chem. Eng. J. 144 (2008) 175-180.

[55] Z. Mu, J.J. Li, Z.P. Hao, S.Z. Qiao, Micropor. Mesopor. Mater. 113 (2008) 72-80.

[56] A.H. Padmasri, A. Venugopal, J. Krishnamurthy, K.S. Rama Rao, P. Kanta Rao, J. Phys. Chem. B 106 (2002) 1024-1031.

[57] F.X. Yin, S.F. Ji, P.Y. Wu, F.Z. Zhao, C.Y. Li, J. Catal. 257 (2008) 108-116.

[58] C. He, J.J. Li, J. Cheng, L.D. Li, P. Li, Z.P. Hao, Z.P. Xu, Ind. Eng. Chem. Res. 48 (2009) 6930-6936.

[59] L.S. Feio, J.C. Escritori, F.B. Noronha, C.E. Hori, Catal. Lett. 120 (2008) 229-235.

[60] C. Leitenburg, A. Trovarelli, J. Llorca, F. Cavani, G. Bini, Appl. Catal. A: Gen. 139 (1996) 161-173.

[61] P. Papaefthimiou, T. Ioannides, X.E. Verykios, Appl. Catal. B: Environ. 13 (1997) $175-184$.

[62] G.S. Wang, W.L. Jae, C.K. Sang, Appl. Catal. B: Environ. 84 (2008) 133-141.

[63] A. Aranzabal, J.A. González-Marcos, J.L. Ayastuy, J.R. González-Velasco, Chem. Eng. Sci. 61 (2006) 3564-3576.

[64] H.L. Tidahy, S. Siffert, J.-F. Lamonier, E.A. Zhilinskaya, A. Aboukaïs, Z.-Y. Yuan, A. Vantomme, B.-L. Su, X. Canet, G. De Weireld, M. Frère, T.B. N'Guyen, J.-M. Giaudon, G. Leclercq, Appl. Catal. A: Gen. 310 (2006) 61-69. 